Research Article

\title{
The Stability Analysis of Tunnel Lining Structure with Seismic Excitation Based on the Energy Evaluation Principle
}

\author{
Yumin Wen, ${ }^{1,2}$ Chunlei Xin $\mathbb{D}^{3,4}$ Xi Zhang, ${ }^{1,2}$ Zeming Huang, ${ }^{3,4}$ Yusheng Shen $\mathbb{D}^{1,2}$ \\ Wenjie Lei, ${ }^{5}$ and Bo Gao ${ }^{2}$ \\ ${ }^{1}$ Key Laboratory of Transportation Tunnel Engineering of the Ministry of Education, Southwest Jiaotong University, \\ Chengdu 610031, China \\ ${ }^{2}$ National Engineering Laboratory for Technology of Geological Disaster Prevention in Land Transportation, \\ Southwest Jiaotong University, Chengdu 610031, China \\ ${ }^{3}$ State Key Laboratory of Geohazard Prevention and Geoenvironment Protection, Chengdu University of Technology, \\ Chengdu 610059, China \\ ${ }^{4}$ College of Environment and Civil Engineering, Chengdu University of Technology, Chengdu 610059, China \\ ${ }^{5}$ College of Water Conservancy and Hydropower Engineering, Sichuan Agricultural University, Ya'an 625000, China
}

Correspondence should be addressed to Chunlei Xin; xinchunlei@cdut.edu.cn

Received 14 March 2021; Accepted 9 July 2021; Published 20 July 2021

Academic Editor: FuRen Ming

Copyright (C) 2021 Yumin Wen et al. This is an open access article distributed under the Creative Commons Attribution License, which permits unrestricted use, distribution, and reproduction in any medium, provided the original work is properly cited.

\begin{abstract}
Earthquakes are vibrations induced by the rapid releases of large quantities of energy from the crustal movements. During seismic excitation, there are kinetic energy, damping energy, and strain energy acting on the tunnel structure. Based on the indexes of the total energy, releasable elastic strain energy, and dissipated energy, this paper proposes three energy evaluation criteria for the tunnel structure, which are applied to the optimization of the aseismic design of the cross-sectional shape and material property of the tunnel structure. It can be concluded that the peak values and accumulated values of elastic strain energy at the spandrel and arch springing are significantly larger than other positions, which indicates that the strengths of the spandrel and arch springing are the most influential factor for the seismic damage of the tunnel structure. Considering this factor, the width-to-height ratio of 1.33 and Poisson's ratio of 0.3 are determined as the most optimal cross-sectional shape and material property, respectively. Furthermore, by analyzing the relationship between the internal energy and the input energy of the tunnel structure with seismic excitation and proposing an equation for the evaluation of the dynamic stability of tunnel structure, the stabilities of the tunnel structure with different PGAs are analyzed; it can be concluded that the larger the peak value of seismic wave acceleration, the longer the instable period and the greater the degree of dynamic instability. The derived equations can be used as references for the seismic analysis of the tunnel structure, and the conclusions of this paper can contribute to the aseismic design of tunnel lining.
\end{abstract}

\section{Introduction}

Energy is an index that describes the state of the whole system [1], which includes the overall dynamic response $[2,3]$, structural parameters [4], and external excitation [5]. Therefore, the mechanism of the instability of structures with seismic excitation can be revealed based on the principle of energy [6].

Originally, the convergence or divergence of the motion index based on the periodic load was proposed to analyze the dynamic response of structures [7]. However, there would be a jump phenomenon when applied to the nonlinear dynamic response analysis [8]. Afterwards, the quasi-static stiffness principle based on the tangent stiffness matrix was proposed $[9,10]$, which could evaluate the dynamic instability conditions of structures [11]. In terms of that principle, the motion equation was transformed to the differential equation of the first order [12], and its stability can be evaluated by the positive definite stability theory of the matrix in motion [13]. Moreover, in regard to the B-R principle, 
incremental dynamic analysis (IDA) curves were used to describe the relation of the strength and displacement [14], which could be effectively used for the dynamic stability analysis of structures. However, the IDA curves occasionally displayed nonmonotonic behaviors and discontinuous points [15]; sometimes, it was difficult to use them to identify the critical strength of structures $[16,17]$, which could influence the dynamic stability analysis of structures [18]; hence, there was no unified quantitative criterion to define the dynamic response of structures based on the B-R principle [19].

Recently, the principle of energy conservation was used to describe the dynamic instability mechanism of structures with seismic excitation $[20,21]$, pointing out that the structures were stable when the input seismic energy was less than the critical value of the energy possessed by the structures [22]. However, it was difficult to determine the critical value of the energy possessed by complex structures with seismic excitation $[23,24]$.

The stability of the tunnel structure with seismic excitation is closely related to the external vibration intensity and internal structural characteristics [25]; it is essential to adopt an appropriate principle to evaluate the stability of the tunnel structure with seismic excitation $[26,27]$. From the perspective of the energy generated from the system and the internal tunnel structure induced by seismic excitation and considering the external vibration intensity and structural characteristics [28], the physical mechanism of seismic instability of complex deformation in the tunnel structure is researched in this paper.

\section{The Methodology}

2.1. Energy Balance Equation of Tunnel Structure. Only considering the single layer structure of tunnel lining, the multi-degree-of-freedom equation of motion can be expressed as follows [29]:

$$
M \ddot{u}(t)+C \dot{u}(t)+f(u, t)=-M r \dot{u}_{g}(t),
$$

where $M$ is the mass matrix, $C$ is the damping matrix, $f(u, t)$ is the internal force, $r$ is the load impact matrix, $\dot{u}_{g}(t)$ is the seismic ground acceleration vector, and $\ddot{u}(t), \dot{u}(t)$, and $u(t)$ are the acceleration, velocity, and displacement vectors, respectively.

Considering that the aseismic stability of the structure is closely related to the internal structural characteristics and external excitation load, integrating the terms in equation (1) over time, the energy equation in the form of work can be obtained as follows [30]:

$$
\int_{0}^{t} \dot{u}^{T} M \ddot{u}(t) \mathrm{d} t+\int_{0}^{t} \dot{u}^{T} C \dot{u}(t) \mathrm{d} t+\int_{0}^{t} \dot{u}^{T} f(u, t) \mathrm{d} t=-\int_{0}^{t} M r \dot{u}_{g}(t) \mathrm{d} t .
$$

Rewriting equation (2) into the energy balance equation, equation (3) can be obtained as follows [31]:

$$
E_{K}(t)+E_{D}(t)+E_{S}(t)=E_{I}(t),
$$

where $E_{K}(t)$ is the kinetic energy, $E_{D}(t)$ is the damping energy, $E_{S}(t)$ is the strain energy, and $E_{I}(t)$ is the input total energy. Each term can be expressed as the following equations, respectively:

$$
\begin{aligned}
& E_{K}(t)=\int_{0}^{t} \dot{u}^{T} M \ddot{u}(t) \mathrm{d} t, \\
& E_{D}(t)=\int_{0}^{t} \dot{u}^{T} C \dot{u}(t) \mathrm{d} t, \\
& E_{S}(t)=\int_{0}^{t} \dot{u}^{T} f(u, t) \mathrm{d} t, \\
& E_{I}(t)=-\int_{0}^{t} M r \dot{u}_{g}(t) \mathrm{d} t .
\end{aligned}
$$

\subsection{Three Energy Evaluation Criteria of the Stability of Tunnel Structure}

2.2.1. Stability Evaluation Criterion Based on the Total Energy. When the structure is motivated by the external excitation [32], there are kinetic energy, damping energy, and strain energy existing inside the structure $[33,34]$. The structure is dynamically stable when the total input energy is equal to the sum of the internal strain energy and dissipated energy [35]. The structure is still dynamically stable when the total input energy is greater than the sum of the internal strain energy and dissipated energy due to the fact that the redundant input energy will transform to other forms of energy to be dissipated $[36,37]$. On the contrary, when the total input energy is less than the sum of the internal strain energy and dissipated energy, the structure is no longer stable and extradeformation will occur to offset the energy difference inside and outside the system. Therefore, the physical mechanism of structural dynamic instability can be attributed to the unbalance of the energy required by structural deformation and external input energy [38]. The state of the dynamic balance can be expressed as

$$
F_{\text {ext }}(t)=F_{\text {int }}(t)
$$

where $F_{\text {ext }}(t)$ is the instantaneous external force vector and $F_{\text {int }}(t)$ is the instantaneous internal force vector. Regarding the structural dynamic force, damping force, and the seismic force as the external force vector and regarding the restoring force generated by structural deformation as the internal force vector, the following equations can be obtained as

$$
\begin{gathered}
F_{\text {ext }}(t)=-M r \dot{u}_{g}(t)-M \ddot{u}(t)-C \dot{u}(t), \\
F_{\text {int }}(t)=f(u, t) .
\end{gathered}
$$

The instantaneous work done by the instantaneous external force vector with seismic excitation can be expressed as

$$
W_{\text {ext }}(t)=\left[-M r \dot{u}_{g}(t)-M \ddot{u}(t)-C \dot{u}(t)\right]^{T} u(t) .
$$

The work done by the restoring force vector of the internal deformation of the structure at a certain time can be expressed as 


$$
W_{\text {int }}(t)=\int_{0}^{u} f(u, t) \mathrm{d} u .
$$

The difference between the instantaneous work done by the external and internal force vectors is denoted as $W(t)$, and equation (13) can be obtained as

$$
W(t)=\left[-M r \dot{u}_{g}(t)-M \ddot{u}(t)-C \dot{u}(t)\right]^{T} u(t)-\int_{0}^{u} f(u, t) \mathrm{d} u .
$$

From the perspective of thermodynamics, the work done by the internal and external forces during an adiabatic process actually represents the variation of the energy rather than the stored energy in the structure [39]. With seismic excitation, the work done by the internal and external forces of the structure is constantly varying, which can be expressed as

$$
E_{\text {intr }}(t)=|W(t)|=\left|W_{\text {ext }}(t)-W_{\text {int }}(t)\right| .
$$

Therein, the input energy of the structure can be calculated by equation (7). The structure is instable when the input energy $E_{I}(t)$ is less than the internal energy $E_{\text {intr }}(t)$; it will absorb extra energy to offset the input energy so that the input energy can be equal to or greater than the intrinsic energy, which represents the dynamic stable state. Therefore, based on the energy evaluation principle, the structural stability can be expressed as

$$
\begin{aligned}
& E_{\text {intr }}(t) \leq E_{I}(t), \text { stable, } \quad t>0, \\
& E_{\text {intr }}(t)>E_{I}(t), \text { instable, } \quad t<0 .
\end{aligned}
$$

Therefore, if the intrinsic energy curve of the structure exceeds the input energy curve, the structure is in a dynamic instable state; the dynamic stability equation can be expressed as

$$
S(t)=E_{I}(t)-E_{\text {intr }}(t),
$$

where the structure is dynamically stable when $S(t) \geq 0$ and the structure is instable when $S(t)<0$.

\subsubsection{Strength Failure Criterion Based on the Dissipated} Energy. According to the law of thermodynamics, energy conversion is an essential feature of the physical process, and substance destruction is a phenomenon of instability induced by energy [40, 41]. According to equation (3), the accumulated elastic strain energy $E_{S}(t)$ can be divided into the elastic strain energy $E_{e}(t)$ and the plastic strain energy $E_{p}(t)$, as shown in

$$
E_{S}(t)=E_{e}(t)+E_{p}(t) .
$$

In the process of element deformation, the elastic strain energy at the elastic stage continues to increase until the yield limit is reached, which means that the elastic strain energy of the element reaches the maximum [42]. When the yield limit is exceeded, the material will undergo an irrecoverable plastic deformation, and it reaches the maximum when the material is almost destroyed, which means that the accumulated plastic strain energy reached the maximum $[43,44]$. With seismic excitation, the structure elements alternatively exhibit tension and compression; they will experience the cycle of loading, compaction, elasticity, plasticity, and unloading, which induces cyclic impact on the material and brings about crack expansion, crack penetration, and even damage of the structure [45].

During seismic excitation, seismic energy is continuously input into the structural system over time; a part of seismic energy is dissipated by the structure through its damping and plastic deformation, and the other part of seismic energy is converted into the kinetic energy of the structure or absorbed in the form of elastic strain energy of the structure [46]. It can be concluded from equation (3) that the total input energy of the structure is converted to the kinetic energy, damping energy, elastic strain energy, and plastic strain energy. In view of that the elastic strain energy and plastic strain energy correspond to the deformation states of the structure, the stability of the structure can be evaluated by calculating the strain energy and analyzing the tendency of the strain energy $[47,48]$.

(1) Strain Energy. The strain energy density can be calculated from the stress and strain of the structure elements, as shown in

$$
w=\int \sigma_{i j} \varepsilon_{i j} \mathrm{~d} \varepsilon_{i j} .
$$

There is a strain equation for the elastoplastic material, as shown in

$$
\varepsilon_{i j}=\varepsilon_{i j}^{e}+\varepsilon_{i j}^{p} .
$$

The strain energy density is expressed as

$$
w=\frac{1}{2} \sigma_{i j} \varepsilon_{i j}^{e}+\sigma_{i j} \varepsilon_{i j}^{p} .
$$

Besides, the strain energy of the element can be expressed as

$$
w_{e}=\int_{V} w \mathrm{~d} v,
$$

where $w$ is the strain energy density of the element and $w_{e}$ is the strain energy of the element.

The total strain energy of the structure can be obtained by summing the strain energy of each element, as shown in

$$
W=\sum w_{e} .
$$

(2) Strength Failure Theory Based on the Dissipated Energy. Considering the deformation of the element with external force, assuming that there is no heat exchange with surrounding, and denoting the total input energy generated by the external force as $U$, the following equation can be obtained according to the first law of thermodynamics as

$$
U=U^{p}+U^{e},
$$

where $U^{p}$ is the plastic strain energy and $U^{e}$ is the releasable elastic strain energy. The plastic strain energy $U^{P}$ is used to form internal damage and plastic deformation, which result in the strength failure, and the release of the elastic strain 
energy $U^{e}$ stored in the element is the underlying reason for the sudden failure of the tunnel element.

The energy of each part of the element in the principal stress space can be expressed as follows:

$$
\begin{aligned}
U & =\int_{0}^{\varepsilon_{1}} \sigma_{1} \mathrm{~d} \varepsilon_{1}+\int_{0}^{\varepsilon_{2}} \sigma_{2} \mathrm{~d} \varepsilon_{2}+\int_{0}^{\varepsilon_{3}} \sigma_{3} \mathrm{~d} \varepsilon_{3}, \\
U^{e} & =\frac{1}{2} \sigma_{1} \varepsilon_{1}^{e}+\frac{1}{2} \sigma_{2} \varepsilon_{2}^{e}+\frac{1}{2} \sigma_{3} \varepsilon_{3}^{e}, \\
U^{p} & =U-U^{e} .
\end{aligned}
$$

The energy damage quantity of the tunnel element can be defined as

$$
\omega=\frac{U^{p}}{U^{c}}
$$

where $U^{c}$ is the critical value of energy dissipation when the element loses its strength, which is a material constant determined by the uniaxial tension test, uniaxial compression test, and pure shear test; the calculation method of $U^{c}$ is same as that of $U^{p}$. When $\Phi=1$, it denotes that the material loses its strength no matter what stress state the material is in, which can be expressed as

$$
\omega=\frac{U^{p}}{U^{c}}=1
$$

Substituting equation (28) into equations (25) and (26), the strength failure criterion based on the dissipated energy can be obtained as

$$
\int_{0}^{\varepsilon_{1}} \sigma_{1} \mathrm{~d} \varepsilon_{1}+\int_{0}^{\varepsilon_{2}} \sigma_{2} \mathrm{~d} \varepsilon_{2}+\int_{0}^{\varepsilon_{3}} \sigma_{3} \mathrm{~d} \varepsilon_{3}-\frac{1}{2} \sigma_{1} \varepsilon_{1}^{e}-\frac{1}{2} \sigma_{2} \varepsilon_{2}^{e}-\frac{1}{2} \sigma_{3} \varepsilon_{3}^{e}=U^{c}
$$

\subsubsection{Overall Failure Criterion Based on the Releasable} Elastic Strain Energy. It can be concluded from equation (25) that the releasable strain energy stored by the element is related to the unloading elastic modulus $E_{i}$ and Poisson's ratio $v$ after damaged. Considering the orthotropy of the element damage, the damage is directly related to the elasticity. Assuming that the compressive stress is positive, when the element is not damaged, it can be expressed as

$$
U^{e}=\frac{1}{2} \sigma_{i} \varepsilon_{i}^{e}=\frac{1}{2}\left\{\frac{\sigma_{1}^{2}}{E_{1}}+\frac{\sigma_{2}^{2}}{E_{2}}+\frac{\sigma_{3}^{2}}{E_{3}}-v\left[\left(\frac{1}{E_{1}}+\frac{1}{E_{2}}\right) \sigma_{1} \sigma_{2}+\left(\frac{1}{E_{1}}+\frac{1}{E_{3}}\right) \sigma_{1} \sigma_{3}+\left(\frac{1}{E_{2}}+\frac{1}{E_{3}}\right) \sigma_{2} \sigma_{3}\right]\right\}
$$

In terms of the damaged structure, the conventional damage variable $\omega_{i}$ is introduced to consider the effect of damage on the unloading modulus $E_{i}$ of the structure, as shown in

$$
E_{i}=\left(1-\omega_{i}\right) E_{0}
$$

where $E_{0}$ is the initial elastic modulus when the structure is not damaged.

Assuming that Poisson's ratio is not affected by the damage and substituting it into equation (30), then the following equation can be obtained as

$$
U^{e}=\frac{1}{2} \sigma_{i} \varepsilon_{i}^{e}=\frac{1}{2 E_{0}}\left\{\frac{\sigma_{1}^{2}}{1-\omega_{1}}+\frac{\sigma_{2}^{2}}{1-\omega_{2}}+\frac{\sigma_{3}^{2}}{1-\omega_{3}}-v\left[\left(\frac{1}{1-\omega_{1}}+\frac{1}{1-\omega_{2}}\right) \sigma_{1} \sigma_{2}+\left(\frac{1}{1-\omega_{1}}+\frac{1}{1-\omega_{3}}\right) \sigma_{1} \sigma_{3}+\left(\frac{1}{1-\omega_{2}}+\frac{1}{1-\omega_{3}}\right) \sigma_{2} \sigma_{3}\right]\right\}
$$

Considering the average effect of the damage along the three directions of the principal stresses, equation (32) can be simplified as

$$
\begin{aligned}
\bar{E} & =E_{0}(1-\bar{\omega}), \\
\bar{v} & =\frac{v}{1-\bar{\omega}}, \\
\omega_{i} & =\bar{\omega}, \quad i=1,2 \text {, and } 3 .
\end{aligned}
$$

The releasable elastic strain energy can be rewritten as

$$
U^{e}=\frac{1}{2 \bar{E}}\left\{\sigma_{1}^{2}+\sigma_{2}^{2}+\sigma_{3}^{2}-2 \bar{v}\left[\sigma_{1} \sigma_{2}+\sigma_{1} \sigma_{3}+\sigma_{2} \sigma_{3}\right]\right\} \text {. }
$$

Herein, the average values $\bar{E}, \bar{v}$, and $\bar{\omega}$ can be determined by the unidirectional cyclic compression loading and unloading tests. It can also be taken as the initial elastic modulus $E_{0}$ and Poisson's ratio $v$ for convenience; then, equation (34) can be rewritten as

$$
U^{e}=\frac{1}{2 E}\left\{\sigma_{1}^{2}+\sigma_{2}^{2}+\sigma_{3}^{2}-2 v\left[\sigma_{1} \sigma_{2}+\sigma_{1} \sigma_{3}+\sigma_{2} \sigma_{3}\right]\right\} .
$$

Equation (35) is aimed at the linear unloading process in the nonlinear process of the element. Summing up the releasable elastic strain energy $U_{i}^{e}$ of each element, the releasable elastic strain energy $\sum U_{i}^{e}$ of the whole structure can be obtained. As the damage of the element increases with external action, the strength gradually decreases; when the releasable elastic strain energy $U_{i}^{e}$ of an element reaches the surface energy $U_{0}$ required by the element damage, $U_{i}^{e}$ will be released in the form of elastic surface energy. When the damaged elements reach a certain critical number, the whole structure will be damaged. 
Based on the above releasable energy concept, the overall failure criterion of the structure element can be concluded that a part of the work done by the external force on the structure is converted into the dissipated energy $U^{p}$, which makes the structure gradually loses its strength, and the other part is converted into the gradually increasing releasable elastic strain energy $U^{e}$. When $U^{e}$ reaches the value of the surface energy $U_{0}$ of the tunnel element, the strain energy $U^{e}$ is released and the whole structure element is damaged. In the principal stress space, $U^{e}$ is difficult to be released along the direction of the maximum compressive stress $\sigma_{1}$, but is apt to be released along the direction of the minimum compressive stress or tensile stress $\sigma_{3}$. The overall failure criteria of the element with compressive stress and tensile stress are given below.

(1) Three-Directional Compressive Stress State $\left(\sigma_{1}>\sigma_{2}>\sigma_{3} \geq 0\right.$, Assuming That the Compressive Stress Is Positive). When the element is in a three-directional compressive stress state and the overall instability occurs, the releasable elastic strain energy will be released along the three directions of stresses. The quantity of the released energy is proportional to the releasable energy stored in the element, and the released strain energy $G_{i}$ along each direction is distributed according to the difference value with the maximum principal stress, which can be expressed as

$$
G_{i}=K_{i}\left(\sigma_{1}-\sigma_{i}\right) U^{e},
$$

where $G_{3}$ is the positive correlation coefficient that can be determined by the uniaxial compression test and $G_{c}$ is the releasable elastic strain energy in the element.

It can be known from equation (36) that the releasable elastic strain energy in the element is primarily released along the third principal stress direction. When the released strain energy along the third principal stress direction $G_{3}$ reaches a critical value $G_{c}$, the releasable elastic strain energy will be released firstly along this direction, which can be expressed as

$$
G_{3}=K_{3}\left(\sigma_{1}-\sigma_{3}\right) U^{e}=G_{c} \text {, }
$$

where $G_{c}$ is the material constant of the element, which can be determined by the uniaxial compression test. When the tunnel element is in the uniaxial compression state, the element will be overall instable if the element undergoes strength failure. Assuming that $\sigma_{1}=\sigma_{c}$ when the element undergoes uniaxial compression strength failure, then $\sigma_{2}=$ $\sigma_{3}=0$ and the following equation can be obtained as

$$
U^{e}=\frac{\sigma_{c}^{2}}{2 E_{0}} .
$$

Substituting equation (38) into equation (37), the following equation can be obtained as

$$
G_{c}=K_{3} \frac{\sigma_{c}^{3}}{2 E_{0}} .
$$

Therefore, the instability criterion of the element in the three-directional compressive stress state can be obtained as

$$
U^{e}=\frac{\sigma_{c}^{2}}{2 E_{0}\left(\sigma_{1}-\sigma_{3}\right)} .
$$

It can be also expressed as

$$
\left(\sigma_{1}-\sigma_{3}\right)\left[\sigma_{1}^{2}+\sigma_{2}^{2}+\sigma_{3}^{2}-2 v\left(\sigma_{1} \sigma_{2}+\sigma_{1} \sigma_{3}+\sigma_{2} \sigma_{3}\right)\right]=\sigma_{c}^{3} .
$$

(2) Stress State with Both Tension and Compression $\left(\sigma_{1}>0, \sigma_{3}<0\right)$. When at least one of the principal stresses is tensile stress, considering that the tensile stress of any magnitude will promote the energy release of the damaged element, the stored releasable strain energy $U^{e}$ is distributed according to the principal stress value along the three directions of principal stress. Therefore, the energy release rate $G_{i}$ of the element along the $\sigma_{i}$ direction can be defined as

$$
G_{i}=K_{i} \sigma_{i} U^{e} .
$$

The releasable elastic strain energy in the element is primarily released along the direction of the maximum principal tensile stress. Therefore, it is necessary to satisfy the following equation when the overall instability occurs:

$$
G_{3}=K_{3} \sigma_{3} U^{e}=G_{t},
$$

where $G_{t}$ is the critical strain energy release rate of the element with tensile stress, which is a material constant determined by the uniaxial tensile test.

When the element is in uniaxial tension state, it will be damaged if the strength is lost. Assuming that $\sigma_{3}=\sigma_{t}, \sigma_{1}=$ $\sigma_{2}=0$ and substituting them into equation (35), the following equation can be obtained as

$$
U^{e}=\frac{\sigma_{t}^{2}}{2 E_{0}} .
$$

Then, substituting it into equation (42), the following equation can be obtained as

$$
G_{t}=K_{3} \frac{\sigma_{t}^{3}}{2 E_{0}}
$$

Moreover, substituting equation (45) into equation (43), the following equation can be obtained as

$$
\sigma_{3} U^{e}=\frac{\sigma_{t}^{3}}{2 E_{0}}
$$

Eventually, substituting equation (46) into equation (35), the overall instability criterion in the stress state with both tension and compression can be obtained as

$$
\sigma_{3}\left[\sigma_{1}^{2}+\sigma_{2}^{2}+\sigma_{3}^{2}-2 v\left(\sigma_{1} \sigma_{2}+\sigma_{1} \sigma_{3}+\sigma_{2} \sigma_{3}\right)\right]=\sigma_{t}^{3} .
$$

\section{Numerical Simulation}

The finite element method (FEM) was employed to conduct the numerical simulation, which had an advantage in solving the simulation of the structure composed of components with different properties. In this series of numerical simulation, stratum-structure model and solid elements were 
adopted to simulate lining structure and surrounding rock, and contact elements were adopted to simulate the slip between lining structure and surrounding rock. Besides, considering the dynamic parameters of the materials, both lining structure and surrounding rock were set as the elastoplastic constitutive model.

\subsection{Tunnel Structures with Cross Sections in Different Ratios of Width to Height}

3.1.1. Finite Element Calculation Model. This paper uses local damping for calculation, which was set as 0.1571 , and the critical damping ratio is taken as $5 \%$ according to the engineering experience. In regard to the boundary conditions, the bottom surface of the model was set as the viscoelastic boundary, and the side surfaces were set as the free field boundary.

Five types of ratios of width to height were established, which were set as $0.68,0.76,0.92,1.33$, and 1.52 , as shown in Figure 1. Considering the Saint-Venant principle, the boundary dimension was set as $50 \mathrm{~m}$ (length) $\times 40 \mathrm{~m}$ (width) $\times 50 \mathrm{~m}$ (height), as shown in Figure 2(a), and the calculation model was composed of 33286 nodes and 29280 elements in total. Furthermore, adopting the solid elements, the Mohr-Coulomb model was used to simulate surrounding rock and initial support, while the elastic constitutive model was used to simulate the lining structure. The physical and mechanical parameters of surrounding rock, initial support, and lining structure were derived from the actual working conditions, and the material of the surrounding rock was strongly weathered sandstone, and the material of the lining structure was C30 concrete, and the specific values of the parameters are listed in Table 1.

3.1.2. Design of Operating Conditions. Analyzing the dynamic response characteristics of tunnel structures in different structural shapes with seismic excitation from the perspective of energy, the optimal tunnel structure shape was researched, and the operating conditions are listed in Table 2.

3.1.3. Monitoring Point Arrangement. A monitoring section was set up at a distance of $20 \mathrm{~m}$ from the tunnel portal, and six monitoring points were set at the crown, left spandrel, right spandrel, left arch springing, right arch springing, and invert, as shown in Figures 2(b) and 2(c).

\subsection{Tunnel Structures with Linings in Different Poisson's} Ratios. Adopting the cross-sectional shape with the width-to-height ratio of 0.92 (shown in Figure 1(c)), the tunnel model with the lining structure in Poisson's ratio of $0.2,0.3$, and 0.4 was established. Considering the SaintVenant principle, the boundary dimension was set as $50 \mathrm{~m}$ (length) $\times 40 \mathrm{~m}$ (width) $\times 50 \mathrm{~m}$ (height), and the calculation model was composed of 33286 nodes and 29280 elements in total. Furthermore, adopting the solid elements, the Mohr-Coulomb model was used to simulate surrounding rock and initial support, while the elastic constitutive model was used to simulate the lining structure.

3.3. Seismic Wave Processing. The Wolong seismic wave in the "5.12" Wenchuan earthquake was selected as the input seismic wave. The original seismic wave was an acceleration wave with a duration of $180 \mathrm{~s}$, whose peak acceleration was $953 \mathrm{~cm} \cdot \mathrm{s}^{-2}$ and occurred at $33.01 \mathrm{~s}$. Considering that the energy of the seismic wave was concentrated in the range of $0-18 \mathrm{~Hz}$, the original seismic wave was processed by baseline correction and the components greater than $18 \mathrm{~Hz}$ were filtered out. Furthermore, the time period of $27.1 \mathrm{~s}-42.1 \mathrm{~s}$ was selected for the dynamic calculation, which included the peak acceleration and most of the energy, then it was multiplied by the reduction coefficient to simulate the seismic response with $0.4 \mathrm{~g}$ PGA. The acceleration time history curve and velocity time history curve obtained after processing are shown in Figure 3. Therein, the velocity wave was input from the bottom of the model after being converted into the stress form.

3.4. Tunnel Structures with Different PGAs. Adopting the operating condition with the width-to-height ratio of 1.33 in Section 3.1 and Poisson's ratio of 0.3 in Section 3.2, seismic waves with PGAs of $0.15 \mathrm{~g}, 0.3 \mathrm{~g}$, and $0.4 \mathrm{~g}$ obtained by being multiplied by different reduction coefficients were input, which were corresponding to seismic fortification intensities of 7, 8, and 9, respectively. The stability of tunnel structures with different PGAs was researched from the perspective of energy.

Considering the Saint-Venant principle, the boundary dimension was set as $50 \mathrm{~m}$ (length) $\times 40 \mathrm{~m}$ (width) $\times 50 \mathrm{~m}$ (height), and the calculation model was composed of 33286 nodes and 29280 elements in total. Furthermore, adopting solid elements, the surrounding rock, initial support, and lining structure were all simulated by the Mohr-Coulomb model.

\section{Analysis of Numerical Simulation Results}

\subsection{Seismic Responses of Tunnel Structures with Different Ratios of Width to Height}

4.1.1. Analysis of Peak Elastic Strain Energy. Extracting three principal stresses of the measuring points at the crown, spandrel, arch springing, and invert corresponding to five types of ratios of width to height with the operating condition of $15 \mathrm{~s}$ Wolong wave and Poisson's ratio of 0.2 , the peak elastic strain energy diagram can be plotted by calculating the elastic strain energy of the elements at the measuring points through equation (21), as illustrated in Figure 4.

The peak values of elastic strain energy at the invert and crown are obviously smaller than those at the spandrel and arch springing, which is due to the fact that the seismic extrusion effect of surrounding rock on both sides of the tunnel structure is stronger than that on the top and bottom 


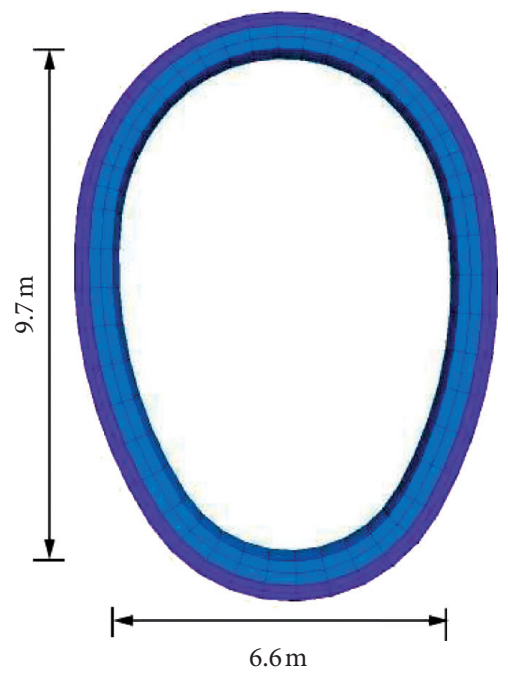

(a)

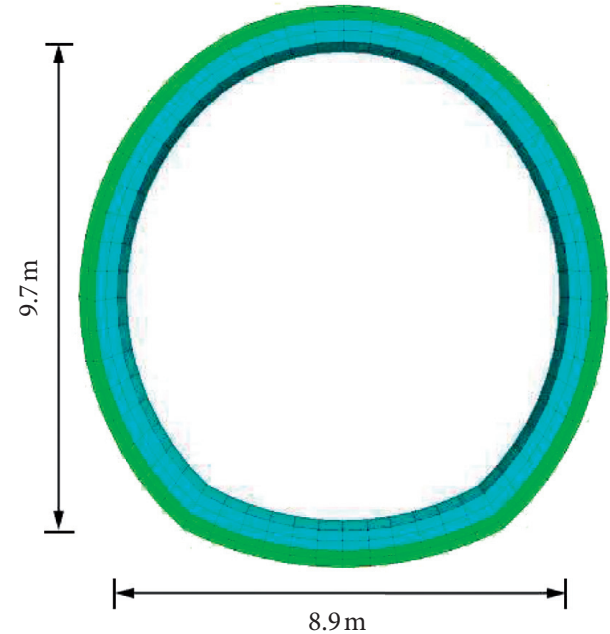

(c)

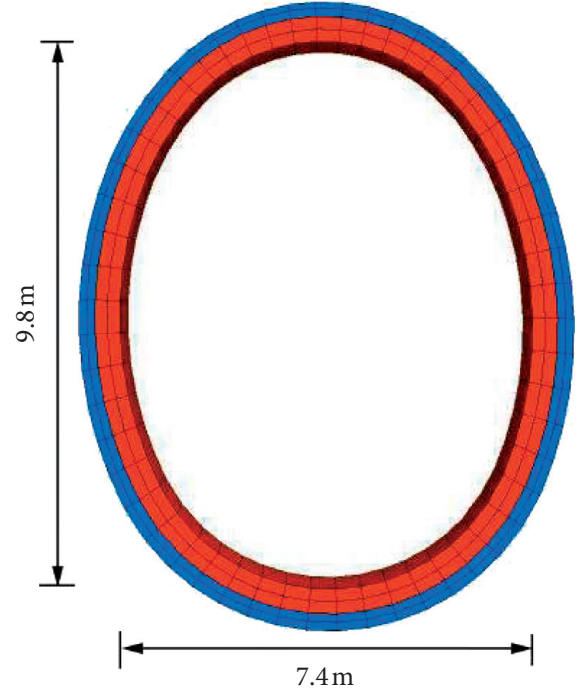

(b)

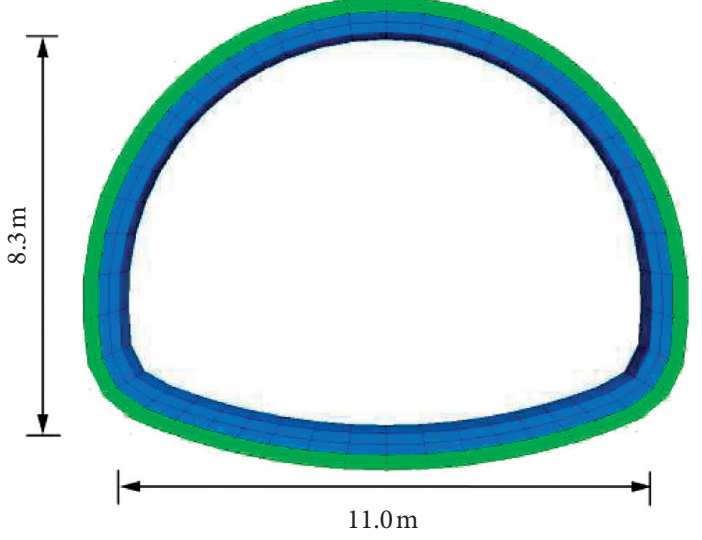

(d)

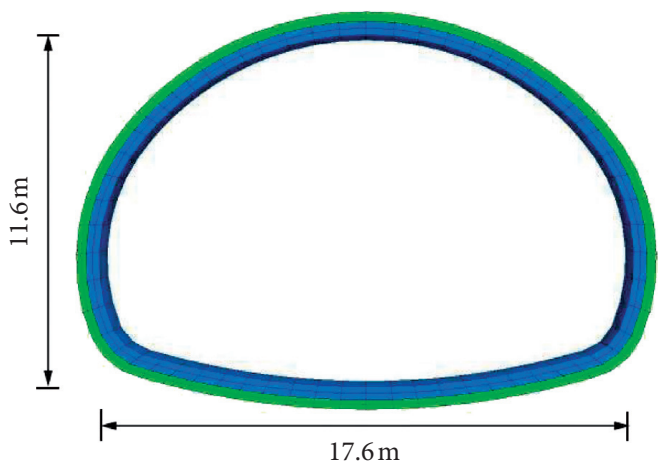

(e)

FIGURE 1: Cross sections in different ratios of width to height. (a) 0.68 ; (b) 0.76 ; (c) 0.92 ; (d) 1.33 ; (e) 1.52 .

of the tunnel structure. As for the crown, the peak elastic strain energy with the operating condition of the width-toheight ratio of 0.76 is the largest. In terms of the invert, the peak elastic strain energy with the operating condition of the width-to-height ratio of 0.92 is the largest, and both the peak elastic strain energy of the crown and invert decreases with the increase of the width-to-height ratio.

In regard to the left spandrel, the peak elastic strain energy with the operating condition of the width-to-height ratio of 1.33 is the smallest, while the peak elastic strain 


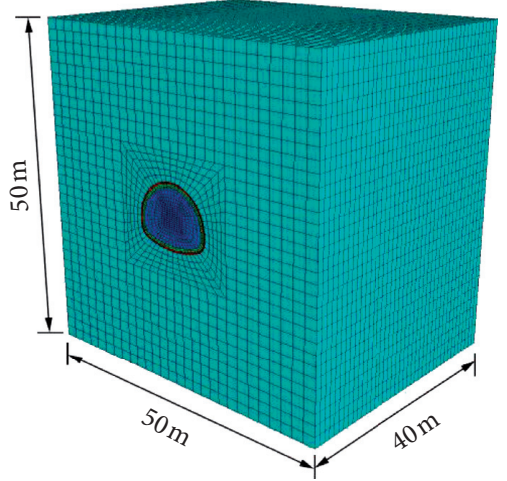

(a)

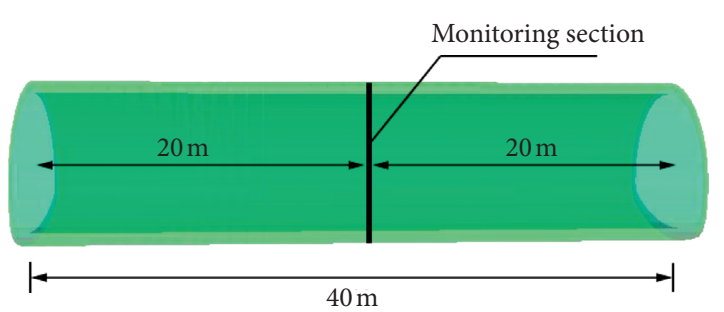

(b)

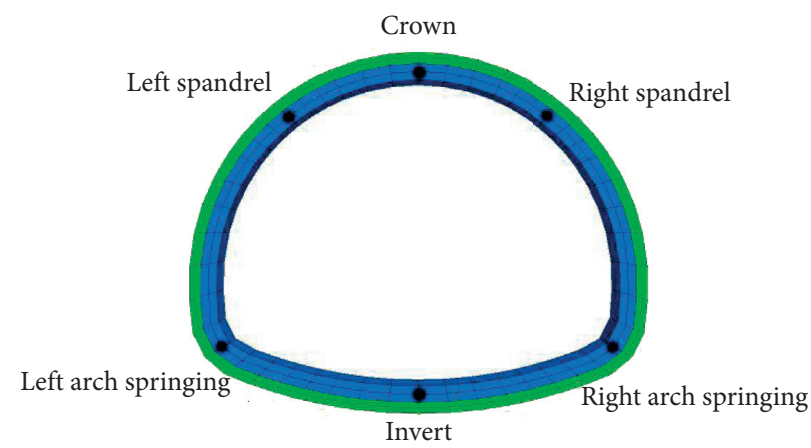

(c)

Figure 2: Calculation model of numerical simulation. (a) Overall model. (b) Monitoring section. (c) Monitoring points.

TABLe 1: Physical and mechanical parameters of surrounding rock, initial support, and lining structure.

\begin{tabular}{lccccc}
\hline Material & Density $\left(\mathrm{kg} \cdot \mathrm{m}^{-3}\right)$ & Elastic modulus $(\mathrm{GPa})$ & Poisson's ratio $(\mu)$ & Cohesion $(\mathrm{MPa})$ & Friction angle $\left(^{\circ}\right)$ \\
\hline Surrounding rock & 2500 & 3 & 0.3 & 0.0044 & 35 \\
Lining structure & 2500 & 30 & $0.2 / 0.3 / 0.4$ & - & - \\
Initial support & 2200 & 20 & 0.3 & 4.4 & 35 \\
\hline
\end{tabular}

TABLE 2: Operating conditions for the dynamic response analysis of tunnel structures in different shapes.

\begin{tabular}{|c|c|c|c|}
\hline Operating condition & Width-to-height ratio & Lining Poisson's ratio & Tunnel form \\
\hline 1 & 0.68 & & \\
\hline 2 & 0.76 & & Two-lane railway tunnel \\
\hline 3 & 0.92 & 0.2 & \\
\hline 4 & 1.33 & & Two-lane highway tunnel \\
\hline 5 & 1.52 & & Four-lane highway tunnel \\
\hline
\end{tabular}

energy with the operating condition of the width-to-height ratio of 0.68 is the largest; what is different is that the peak elastic strain energy increases with the increase of the widthto-height ratio when the width-to-height ratio is greater than 1. The seismic response of the right spandrel is similar to that of the left spandrel; the only difference is that the peak elastic strain energy of the right spandrel reaches the maximum at the operating condition of the width-to-height ratio of 1.52.

Furthermore, the peak elastic strain energy of the arch springing is generally larger than that of other positions, which indicates that the energy generated by seismic excitation mostly concentrates at the arch springing. Besides, the peak elastic strain energy increases with the increase of the width-to-height ratio when the width-to-height ratio is smaller than 1, and it reaches the maximum at the operating condition of the width-to-height ratio of 0.92 , and the peak elastic strain energy with the operating condition of the width-to-height ratio of 1.33 is smaller than that of the width-to-height ratio of 1.52 .

In summary, comparing the operating conditions of different ratios of width to height at different positions of the tunnel structure, one can see that the peak elastic strain energy with the operating condition of the width-to-height ratio of 1.33 is the smallest, which indicates that the cross- 


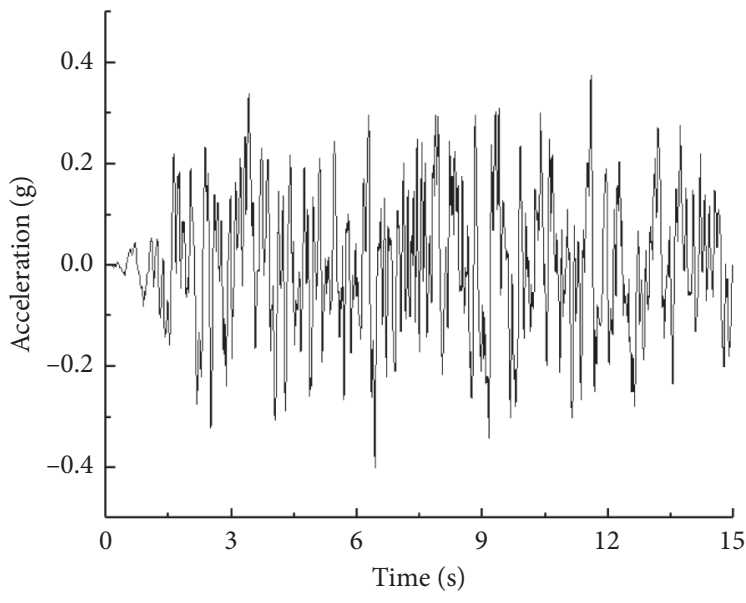

(a)

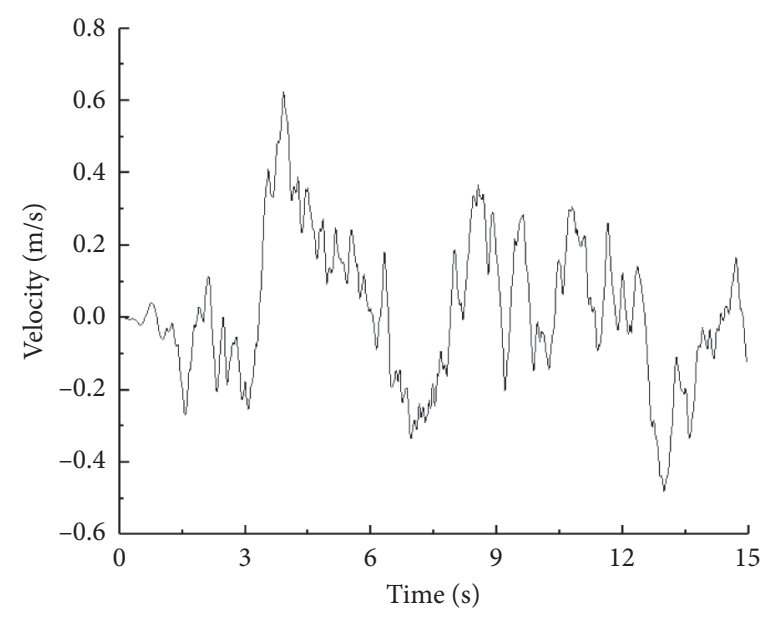

(b)

FIgURE 3: Time history curves of the input seismic wave. (a) Acceleration time history curve. (b) Velocity time history curve.

sectional shape can effectively reduce the elastic strain energy concentrating on the tunnel structure with seismic excitation, and the shape of the width-to-height ratio of 1.33 is the optimal tunnel cross-sectional shape.

4.1.2. Analysis of Accumulated Elastic Strain Energy. The accumulated elastic strain energy after inputting the $15 \mathrm{~s}$ seismic wave at the six monitoring points of the tunnel structure was plotted in Figure 5. With the increase of the width-to-height ratio, the accumulated elastic strain energy of the crown and invert gradually decreases, whereas the accumulated elastic strain energy of the spandrel and arch springing gradually increases, and the strain state with seismic excitation gradually transferred from the crown and invert alternatively expanding and contracting to the spandrel and arch springing alternatively expanding and contracting.

As for the crown, the accumulated elastic strain energy with the operating condition of the width-to-height ratio of 0.76 is the largest, and the accumulated elastic strain energy gradually decreases with the increase of the width-to-height ratio when the width-to-height ratio is greater than 1 . In terms of the invert, the accumulated elastic strain energy with the operating condition of the width-to-height ratio of 0.92 is the largest, and the accumulated elastic strain energy with the operating condition of the width-to-height ratio of 1.33 is smaller than that of the width-to-height ratio of 1.52 , which indicates that the seismic performance of the shape of the width-to-height ratio of 1.33 is better than that of the width-to-height ratio of 1.52.

The accumulated elastic strain energy of the spandrel and arch springing is obviously greater than that of the invert and crown. The accumulated elastic strain energy of the left spandrel, left arch springing, and right arch springing with the operating condition of the width-to-height ratio of 1.33 is the smallest, while the accumulated elastic strain energy of the right spandrel is also relatively small. Therefore, it can be concluded that the cross section in the width-to-height ratio of 1.33 has the best seismic performance.

\subsection{Seismic Responses of Tunnel Structures with Linings in Different Poisson's Ratios}

4.2.1. Analysis of Peak Elastic Strain Energy. Extracting three principal stresses of the measuring points at the crown, spandrel, arch springing, and invert corresponding to three types of Poisson's ratios with the operating condition of $15 \mathrm{~s}$ Wolong wave and the widthto-height ratio of 0.92 , the peak elastic strain energy diagram can be plotted by calculating the elastic strain energy of the elements at the measuring points through equation (21), as illustrated in Figure 6.

With the operating conditions of three different Poisson's ratios, the peak values of elastic strain energy at the invert and crown are all smaller than that at the spandrel and arch springing. The peak elastic strain energy at the crown, invert, and left spandrel slightly decreases with the operating condition of Poisson's ratio of 0.3 , and the peak elastic strain energy at other positions increases, whereas the seismic response with the operating condition of Poisson's ratio of 0.4 is on the contrary. Considering that the peak elastic strain energy at the arch springing is the largest, it is determined that Poisson's ratio of 0.4 is most optimal Poisson's ratio.

4.2.2. Analysis of Accumulated Elastic Strain Energy. The accumulated elastic strain energy after inputting the $15 \mathrm{~s}$ seismic wave at the six monitoring points of the tunnel structure is plotted in Figure 7. Different from the distribution trend of the peak elastic strain energy, the accumulated elastic strain energy at the spandrel is greater than that of arch springing, which indicates that the cyclic deformation of spandrel is greater than that of arch springing. With the increase of Poisson's ratio, the accumulated elastic strain energy of the crown increases greatly, indicating that the increase of Poisson's ratio is unfavorable to the stability of the crown.

The variations of the positions except the crown are stable when Poisson's ratio is 0.3 , and the increase and 


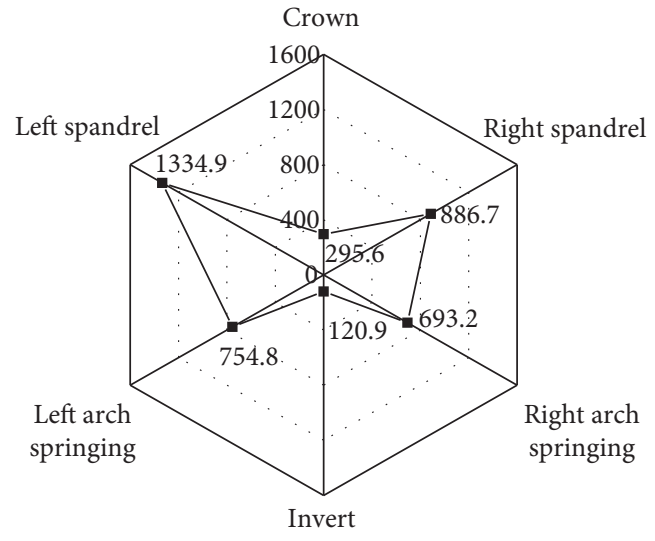

(a)

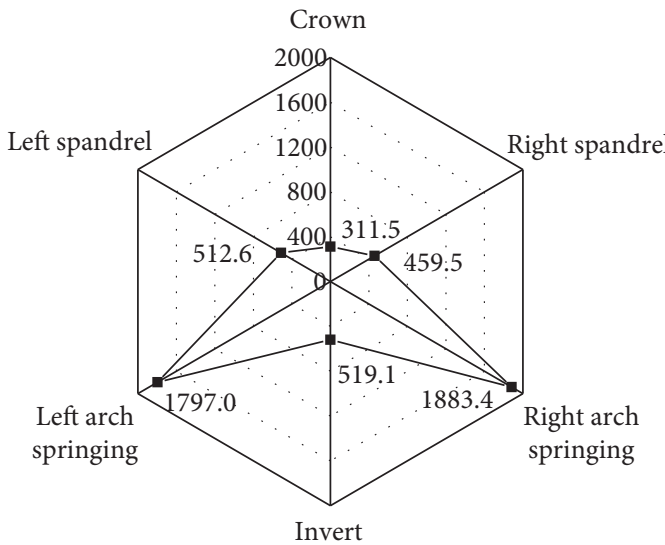

(c)

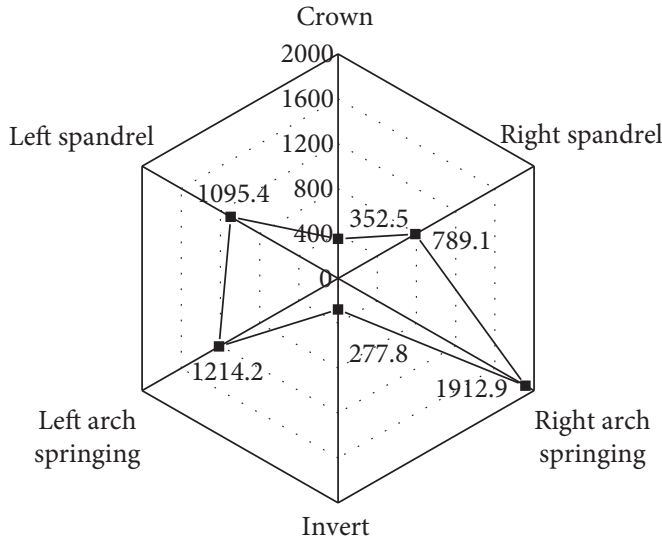

(b)

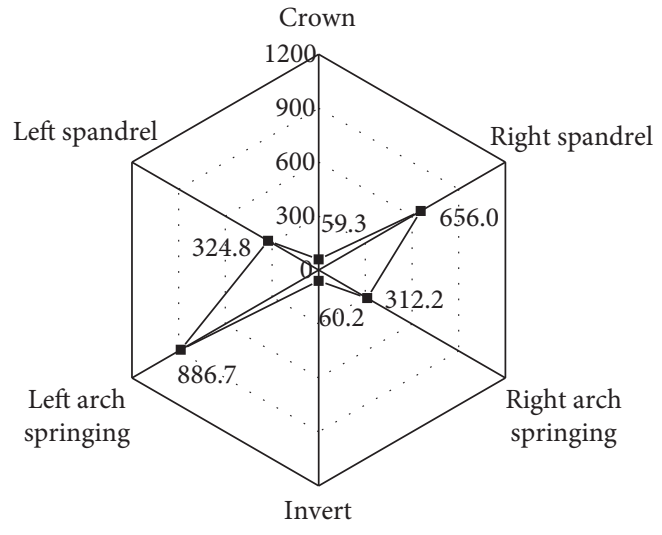

(d)

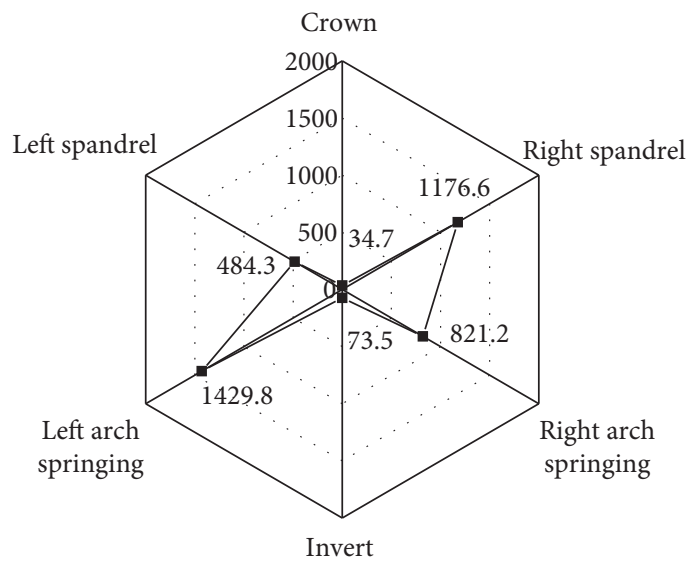

(e)

FiguRE 4: Peak elastic strain energy diagrams of tunnel structures with different ratios of width to height (unit: J). (a) 0.68 ; (b) 0.76; (c) 0.92; (d) 1.33 ; (e) 1.52 .

decrease of the accumulated elastic strain energy are relatively small. When Poisson's ratio is 0.4 , the accumulated elastic strain energy at the crown increases significantly, and the accumulated elastic strain energy at the right spandrel also increases. The maximum value of the accumulated elastic strain energy with the operating conditions of three Poisson's ratios all occurs at the right spandrel, and when Poisson's ratio is 0.3 , it is less than the value when Poisson's ratio is 0.4. In summary, Poisson's ratio of 0.3 is most optimal Poisson's ratio for the aseismic design.

4.3. Seismic Responses of Tunnel Structures with Different $P G A s$. Analyzing the total seismic input energy, kinetic energy, damping energy, and strain energy in the energy balance equation, the energy responses of tunnel structures 


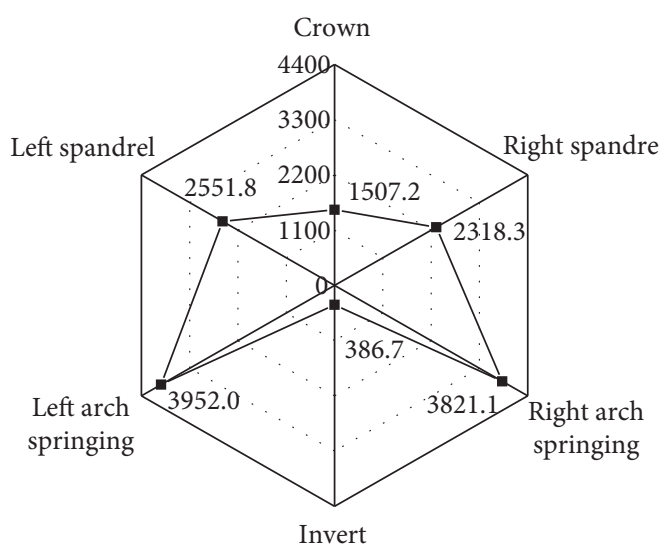

(a)

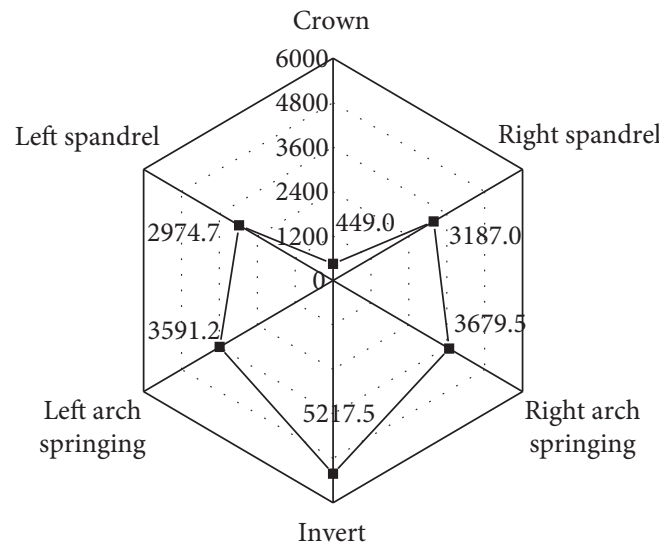

(c)

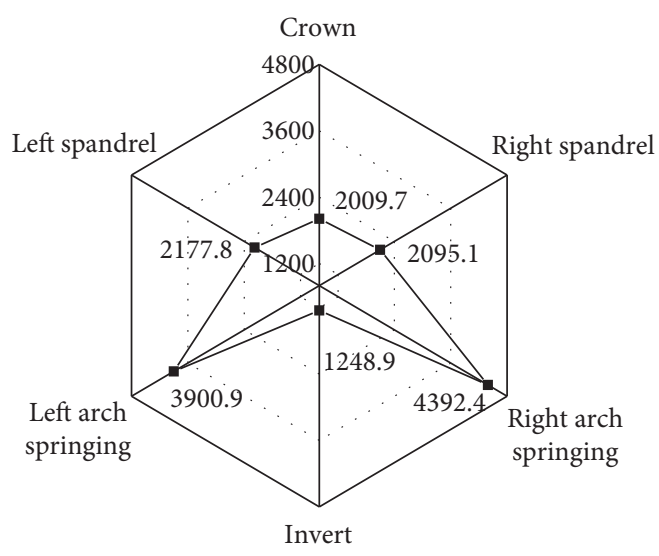

(b)

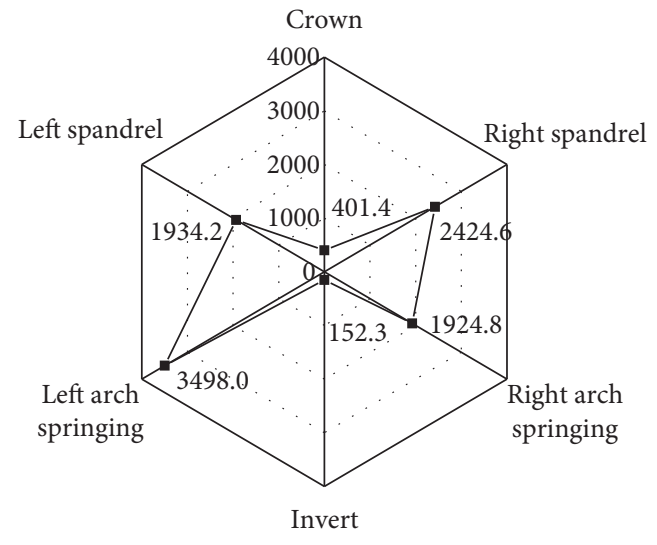

(d)

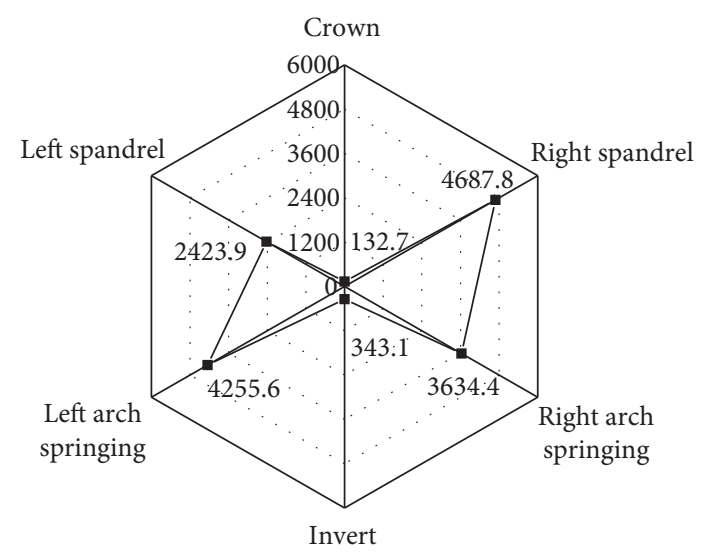

(e)

FIGURE 5: Accumulated elastic strain energy diagrams of tunnel structures with different ratios of width to height (unit: J). (a) 0.68 ; (b) 0.76 ; (c) 0.92 ; (d) 1.33 ; (e) 1.52 .

with different PGAs are researched, and a structural dynamic stability function based on the energy is established to evaluate the safety and stability of the tunnel structure with seismic excitation.

With seismic excitation, the tunnel structure is in an energy field, and the effect of the earthquake on the structure is a process of transferring and transformation of energy. According to the derivation in Section 2.2, when the total input energy is greater than or equal to the energy generated inside the structure with seismic excitation, the structure can maintain a dynamic balance state, which can be expressed as

$$
E_{I} \geq E_{S}+E_{P}+E_{D}+E_{K}
$$

where $E_{I}$ is the total input energy, $E_{S}$ is the elastic strain energy, $E_{P}$ is the plastic strain energy, $E_{D}$ is the damping energy, $E_{K}$ is the kinetic energy, and the sum of the elastic 


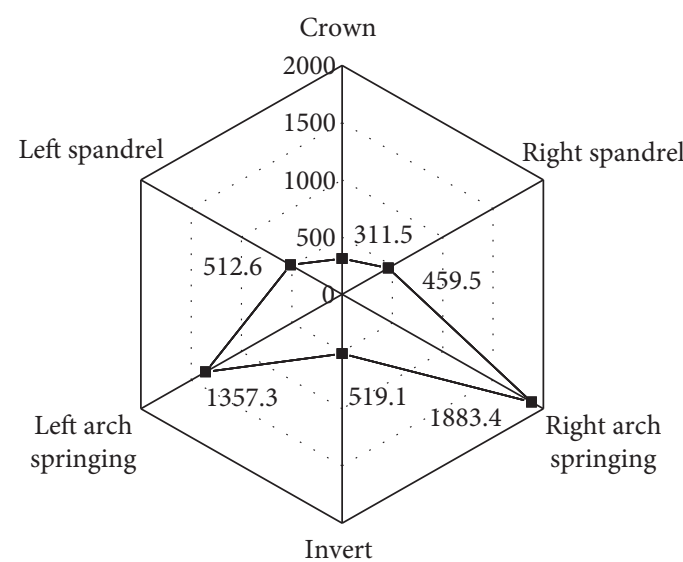

(a)

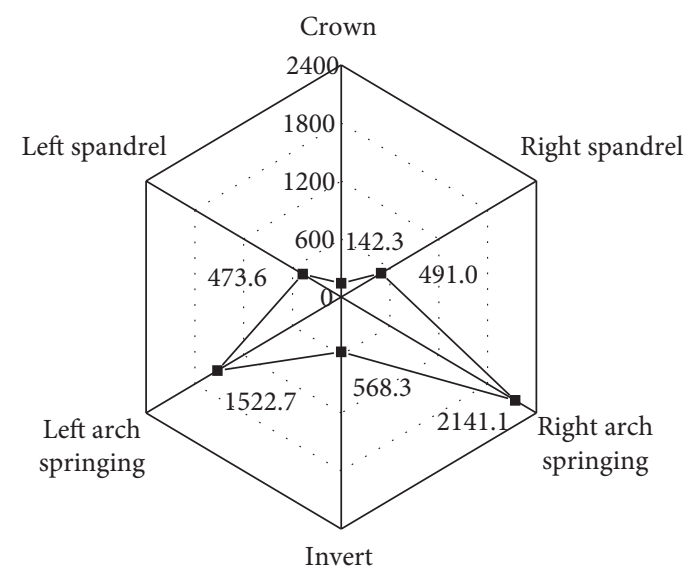

(b)

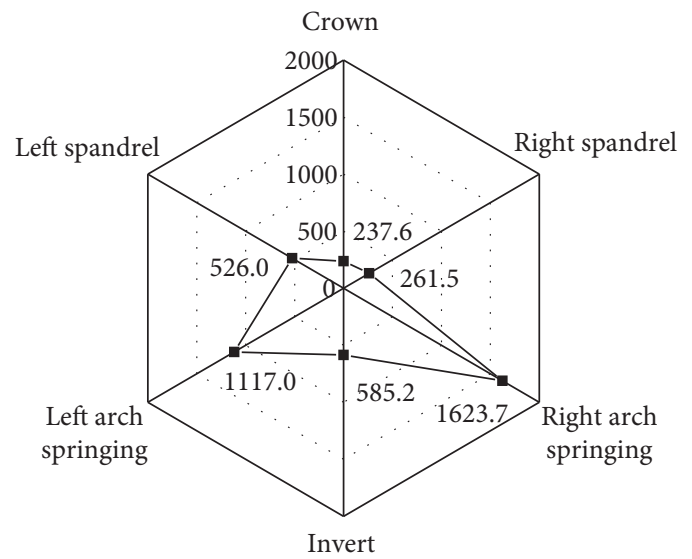

(c)

Figure 6: Peak elastic strain energy diagrams of tunnel structures with different Poisson's ratios (unit: J). (a) 0.2; (b) 0.3 ; (c) 0.4 .

strain energy $E_{S}$ and the plastic strain energy $E_{P}$ is called the strain energy $E_{N}$.

4.3.1. Energy Response of Dynamic Process. Inputting the seismic wave with the peak acceleration of $0.15 \mathrm{~g}, 0.3 \mathrm{~g}$, and $0.4 \mathrm{~g}$, for most of the time, the energy of the lining structure has the trend of kinetic energy $>$ damping energy $>$ strain energy. Besides, the energy increases with the increase of the peak acceleration of the input seismic wave. In order to observe the variation of energy with the increase of the peak acceleration of the input seismic wave, the maximum and secondary maximum of each energy are listed in Table 3.

The kinetic energy, damping energy, and strain energy all increase significantly with the increase of the peak acceleration of input seismic wave. For example, when the PGA increases from $0.15 \mathrm{~g}$ to $0.3 \mathrm{~g}$, the kinetic energy, damping energy, and strain energy increase by $300 \%, 302 \%$, and $297 \%$, respectively. When the PGA increases from $0.3 \mathrm{~g}$ to $0.4 \mathrm{~g}$, the kinetic energy, damping energy, and strain energy all increase by $78 \%$.

Considering that the proportions of each energy of the lining structure in the total input energy with the PGAs of $0.15 \mathrm{~g}, 0.3 \mathrm{~g}$, and $0.4 \mathrm{~g}$ are $56.8 \%, 56.7 \%$, and $36.5 \%$ for the kinetic energy, $21.6 \%, 21.6 \%$, and $13.9 \%$ for the damping energy, and $10.0 \%, 9.9 \%$, and $6.4 \%$ for the strain energy, the proportions of each energy decreases significantly when the peak acceleration of the input seismic wave increases to $0.4 \mathrm{~g}$, which is due to the fact that the energy is dissipated by the instability of the tunnel structure.

At the end of the dynamic calculation, the accumulated value of each energy with the PGAs of $0.15 \mathrm{~g}, 0.3 \mathrm{~g}$, and $0.4 \mathrm{~g}$ is shown in Figure 8 .

The kinetic energy has a rapider growth trend during the dynamic process, whereas the damping energy and elastic strain energy have a much slower growth trend and the plastic strain energy is very small throughout the whole process, which indicates that the lining structure has little plastic deformation. In addition, with the increase of PGA, the proportions of each energy decreases whereas the total input energy increases, which indicates that the larger the PGA, the more likely the energy of the structure will be lost due to the instability.

4.3.2. Energy Dynamic Stability Equation of Lining Structure. In order to observe clearly whether the tunnel structure is instable and the corresponding period of instability, the dynamic stability equation of the lining structure can be obtained as 


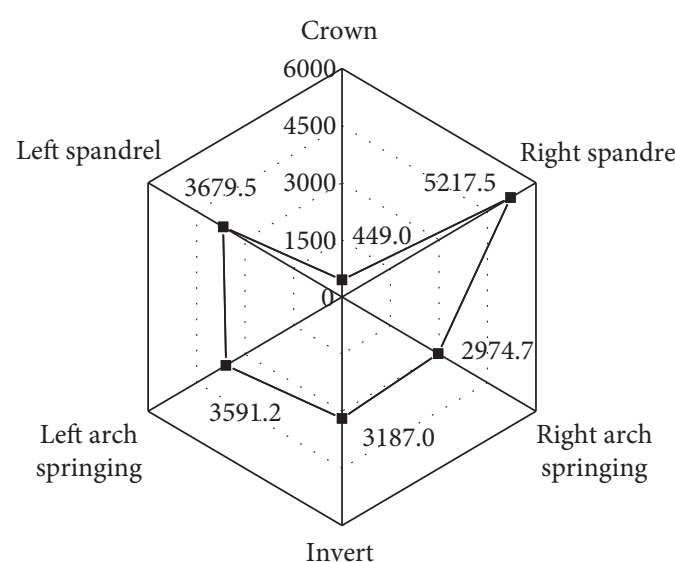

(a)

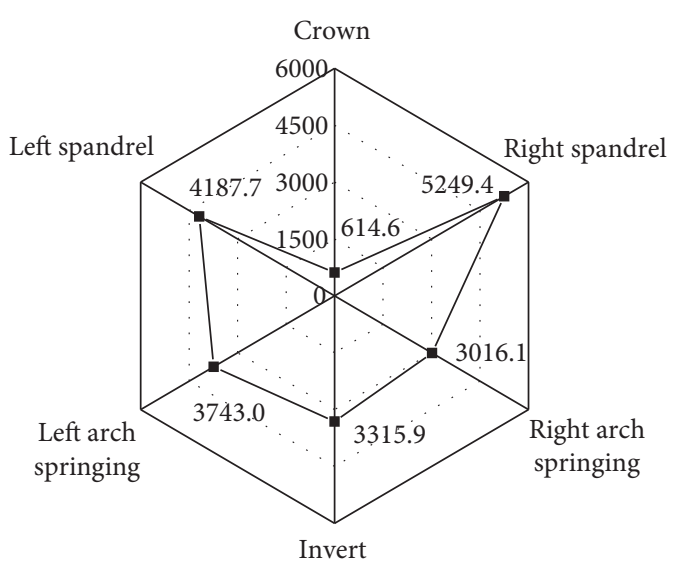

(b)

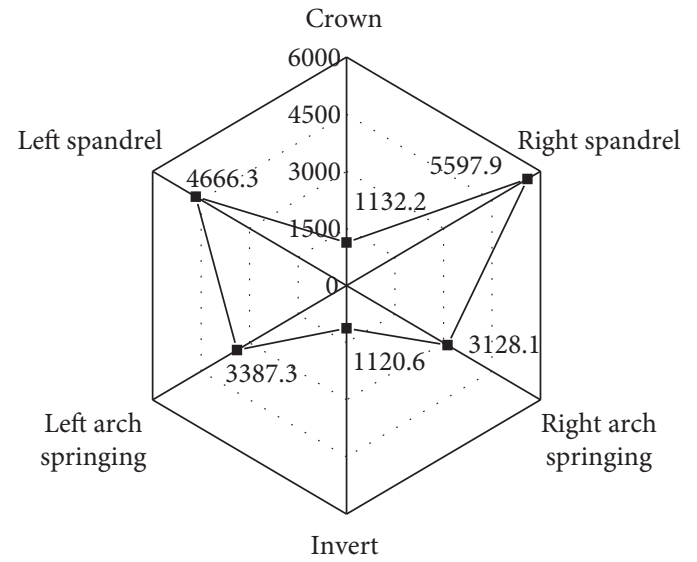

(c)

Figure 7: Accumulated elastic strain energy diagrams of tunnel structures with different Poisson's ratios (unit: J). (a) 0.2; (b) 0.3; (c) 0.4.

TABLE 3: The maximum and secondary maximum of each energy (unit: $10^{10} \mathrm{~J}$ ).

\begin{tabular}{|c|c|c|c|c|c|}
\hline Operating condition $(\mathrm{g})$ & & Total input energy $E_{I}$ & Kinetic energy $E_{K}$ & Damping energy $E_{D}$ & Strain energy $E_{N}$ \\
\hline \multirow{2}{*}{0.15} & Maximum & 32.9 & 18.7 & 7.1 & 3.3 \\
\hline & Secondary maximum & 19.1 & 10.3 & 4.1 & 3.0 \\
\hline \multirow{2}{*}{0.3} & Maximum & 131.8 & 74.8 & 28.5 & 13.1 \\
\hline & Secondary maximum & 77.2 & 42.1 & 16.1 & 11.7 \\
\hline \multirow{2}{*}{0.4} & Maximum & 364.6 & 133 & 50.7 & 23.3 \\
\hline & Secondary maximum & 214.2 & 73 & 30.2 & 21.5 \\
\hline
\end{tabular}

$$
S(t)=E_{I}(t)-E_{\text {intr }}(t)
$$

The internal energy $E_{\text {intr }}(t)$ can be obtained by equation (14), and the dynamic stability equation curves with different PGAs are shown in Figure 9, where the red lines in the diagrams represent the critical value of tunnel stability.

It is known from equation (16) that the structure is stable when $S(t) \geq 0$ and is instable when $S(t)<0$, and the value of $S(t)$ can be used to evaluate the stability of the lining structure. As shown in Figure 9, the lining structure is stable for most of the time, and it is instable only at about $2 \mathrm{~s}, 3.2 \mathrm{~s}$, $6.5 \mathrm{~s}, 8 \mathrm{~s}$, and $11.2 \mathrm{~s}$. The instability of the lining structure is the most serious at about $11.2 \mathrm{~s}$ with all the three PGAs, which is consistent with the seismic performance in the actual event, while the minimum values of $S(t)$ for the PGAs of $0.15 \mathrm{~g}, 0.3 \mathrm{~g}$, and $0.4 \mathrm{~g}$ are $-2.79 \times 10^{10},-1.30 \times 10^{11}$, and $-2.43 \times 10^{11}$, respectively. It can be concluded that the proposed equation can accurately evaluate the stability of the tunnel structure, and the instability degree of the tunnel structure can be represented by the specific value. 


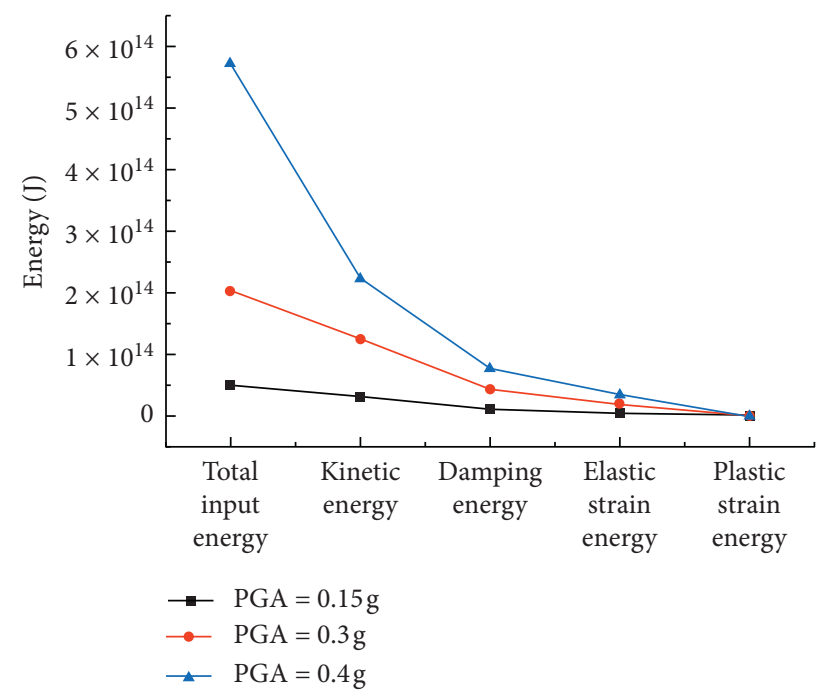

Figure 8: Accumulated values of the energy with different PGAs.

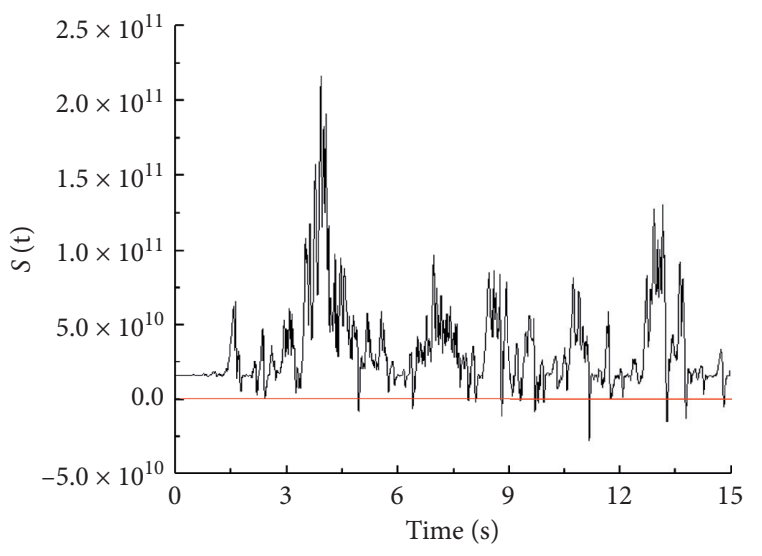

(a)

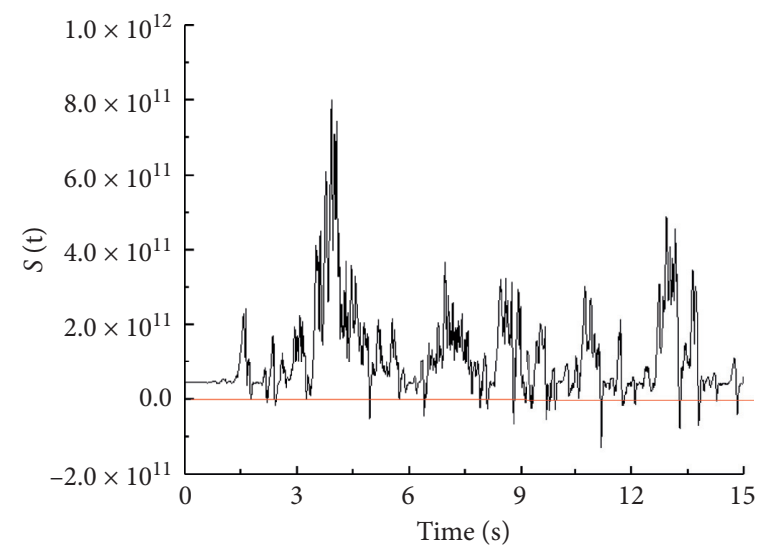

(b)

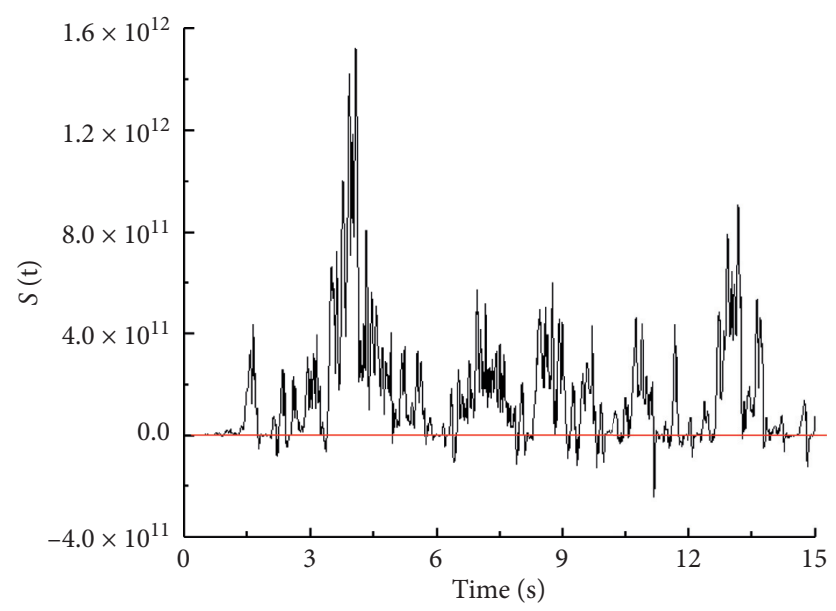

(c)

Figure 9: Dynamic stability equation curves with different PGAs (unit: J). (a) $0.15 \mathrm{~g}$; (b) $0.3 \mathrm{~g}$; (c) $0.4 \mathrm{~g}$. 
Furthermore, the larger the peak value of seismic wave acceleration, the longer period of the tunnel structure is instable and the greater the degree of dynamic instability.

\section{Conclusions}

Beginning from the energy balance equation of the tunnel structure, this paper analyzed the relationship between the internal energy and the input energy of tunnel structure with seismic excitation and proposed equations for the evaluation of the dynamic stability of the tunnel structure. Based on the indexes of the releasable elastic strain energy and dissipated energy, the strength failure criterion of the tunnel structure was proposed, which was applied to the optimization of the aseismic design of the cross-sectional shape and material property of the tunnel structure. Besides, the stability of the tunnel structure with different PGAs based on the energy dynamic stability equation was analyzed. The conclusions are summarized as follows:

(1) The energy balance equation with seismic excitation is established for the tunnel structure. Further, the structure stability evaluation index is proposed from the perspective of the total energy balance of the system, and the tunnel strength failure criterion is proposed from the perspective of irreversible dissipation energy and releasable elastic strain energy.

(2) The releasable elastic strain energy index is used to optimize the cross-sectional shape of the tunnel structure. It is concluded that the peak values and accumulated values of elastic strain energy at the spandrel and arch springing are significantly larger than other positions, which indicates that the strengths of the spandrel and arch springing are the most influential factor for the seismic damage of the tunnel structure. Considering this factor, the widthto-height ratio of 1.33 is determined as the most optimal cross-sectional shape.

(3) The releasable elastic strain energy index is used to optimize the material property of the tunnel structure. It is shown that the peak elastic strain energy of the arch springing is the largest, while the accumulated elastic strain energy of the spandrel is the largest. Comparing the variations of the elastic strain energy with different operating conditions, Poisson's ratio of 0.3 is determined as the most optimal material property.

(4) The seismic responses of the total input energy, kinetic energy, damping energy, and strain energy of the tunnel structure with different PGAs are analyzed. From the perspective of the total energy balance of the system and applying the energy dynamic stability equation derived by analyzing the relationship between the internal energy and the total input energy, the stability of the tunnel structure is analyzed. It can be concluded that the larger the peak value of seismic wave acceleration, the longer period of the tunnel structure is instable and the greater the degree of dynamic instability.

\section{Data Availability}

The data used to support the findings of the study are available from the corresponding author upon request.

\section{Conflicts of Interest}

The authors declare that they have no conflicts of interest.

\section{Acknowledgments}

This research was supported by the Miaozi Engineering Key Project from Science and Technology Department of Sichuan Province (Grant no. 2020JDRC0078), State Key Laboratory of Geohazard Prevention and Geoenvironment Protection (China) Open Fund (Grant no. SKLGP2020K018), and National Natural Science Foundation of China (Grant nos. 51678501 and 51778540).

\section{References}

[1] C. Delmastro, E. Lavagno, and L. Schranz, "Energy and underground," Tunnelling and Underground Space Technology, vol. 55, pp. 96-102, 2016.

[2] C. L. Xin, Z. Z. Wang, and B. Gao, "Shaking table tests on seismic response and damage mode of tunnel linings in diverse tunnel-void interaction states," Tunnelling and Underground Space Technology, vol. 77, pp. 295-304, 2018.

[3] C. L. Xin, Z. Z. Wang, J. M. Zhou, and B. Gao, "Shaking table tests on seismic behavior of polypropylene fiber reinforced concrete tunnel lining," Tunnelling and Underground Space Technology, vol. 88, pp. 1-15, 2019.

[4] Y. S. Shen, Z. Z. Wang, J. Yu, X. Zhang, and B. Gao, "Shaking table test on flexible joints of mountain tunnels passing through normal fault," Tunnelling and Underground Space Technology, vol. 98, Article ID 103299, 2020.

[5] J. Chen, H. Yu, A. Bobet, and Y. Yuan, "Shaking table tests of transition tunnel connecting TBM and drill-and-blast tunnels," Tunnelling and Underground Space Technology, vol. 96, Article ID 103197, 2020.

[6] C.-B. Qin and S. C. Chian, "Kinematic analysis of seismic slope stability with a discretisation technique and pseudodynamic approach: a new perspective," Géotechnique, vol. 68, no. 6, pp. 492-503, 2018.

[7] A. M. Lyapunov, "The general problem of the stability of motion," International Journal of Control, vol. 55, no. 3, pp. 531-534, 1992.

[8] J.-s. Xu, Y.-x. Li, and X.-l. Yang, "Seismic and static 3D stability of two-stage slope considering joined influences of nonlinearity and dilatancy," KSCE Journal of Civil Engineering, vol. 22, no. 10, pp. 3827-3836, 2018.

[9] C.-T. Hou and X.-L. Yang, "Seismic stability of 3D tunnel face considering tensile strength cut-off," KSCE Journal of Civil Engineering, vol. 24, no. 7, pp. 2232-2243, 2020.

[10] C. L. Xin, Z. Z. Wang, and J. Yu, "The evaluation on shock absorption performance of buffer layer around the cross section of tunnel lining," Soil Dynamics and Earthquake Engineering, vol. 131, Article ID 106032, 2020.

[11] G.-H. Zhang, Y.-Y. Jiao, and H. Wang, "Outstanding issues in excavation of deep and long rock tunnels: a case study," 
Canadian Geotechnical Journal, vol. 51, no. 9, pp. 984-994, 2014.

[12] Q. Zheng, C. L. Xin, Y. S. Shen, Z. M. Huang, and B. Gao, "Seismic damage prediction method for lining structures based on the SEDR principle," Shock and Vibration, vol. 2021, Article ID 6637909, 13 pages, 2021.

[13] Z. He and Q. Chen, "Upgrading the seismic performance of underground structures by introducing lead-filled steel tube dampers," Tunnelling and Underground Space Technology, vol. 108, Article ID 103727, 2021.

[14] D. Deniz, J. Song, and J. F. Hajjar, "Energy-based seismic collapse criterion for ductile planar structural frames," Engineering Structures, vol. 141, pp. 1-13, 2017.

[15] Z. Z. Wang, L. Jiang, and Y. Gao, "Shaking table test of seismic response of immersed tunnels under effect of water," Soil Dynamics and Earthquake Engineering, vol. 116, pp. 436-445, 2019.

[16] L. Dong, Q. Hu, X. Tong, and Y. Liu, "Velocity-free MS/AE source location method for three-dimensional hole-containing structures," Engineering, vol. 6, no. 7, pp. 827-834, 2020.

[17] J. Ma, L. Dong, G. Zhao, and X. Li, "Focal mechanism of mining-induced seismicity in fault zones: a case study of Yongshaba mine in China," Rock Mechanics and Rock Engineering, vol. 52, no. 9, pp. 3341-3352, 2019.

[18] J. Zhang, Y. Yuan, Z. Bao, H. Yu, and E. Bilotta, "Shaking table tests on shaft-tunnel junction under longitudinal excitations," Soil Dynamics and Earthquake Engineering, vol. 132, Article ID 106055, 2020.

[19] J. Zhang, Y. Yuan, E. Bilotta, and H. Yu, "Analytical solutions for seismic responses of shaft-tunnel junction under longitudinal excitations," Soil Dynamics and Earthquake Engineering, vol. 131, Article ID 106033, 2020b.

[20] S. M. Holzer, "Static and dynamic stability of reticulated shells," in Proceedings of International Colloqium on Stability of Structures under Static and Dynamic Loads, Washington, DC, USA, 1977.

[21] J. M. Mayoral and G. Mosqueda, "Seismic interaction of tunnel-building systems on soft clay," Soil Dynamics and Earthquake Engineering, vol. 139, Article ID 106419, 2020.

[22] L. Tao, P. Ding, X. Yang et al., "Comparative study of the seismic performance of prefabricated and cast-in-place subway station structures by shaking table test," Tunnelling and Underground Space Technology, vol. 105, Article ID 103583, 2020.

[23] J. J. Zhang, J. Y. Niu, X. Fu, L. C. Cao, and S. J. Yan, "Failure modes of slope stabilized by frame beam with prestressed anchors," European Journal of Environmental and Civil Engineering, pp. 1-23, 2020.

[24] S. Zhang, Y. Yuan, C. Li, Y. Yang, H. Yu, and H. A. Mang, "Effects of interior structure as double deck lanes on seismic performance of segmental linings," Tunnelling and Underground Space Technology, vol. 103, Article ID 103441, 2020.

[25] Z. Chen, W. Chen, Y. Li, and Y. Yuan, "Shaking table test of a multi-story subway station under pulse-like ground motions," Soil Dynamics and Earthquake Engineering, vol. 82, pp. 111122, 2016.

[26] B. Li, N. Xu, F. Dai, G. Zhang, and P. Xiao, "Dynamic analysis of rock mass deformation in large underground caverns considering microseismic data," International Journal of Rock Mechanics and Mining Sciences, vol. 122, Article ID 104078, 2019.

[27] Z. M. Shi, X. Xiong, M. Peng et al., "Risk assessment and mitigation for the Hongshiyan landslide dam triggered by the
2014 Ludian earthquake in Yunnan, China," Landslides, vol. 14, no. 1, pp. 269-285, 2016.

[28] H. Yu, X. Chen, and Y. Sun, "A generalized bond-based peridynamic model for quasi-brittle materials enriched with bond tension-rotation-shear coupling effects," Computer Methods in Applied Mechanics and Engineering, vol. 372, Article ID 113405, 2020.

[29] D. E. Hudson, "Dynamics of structures: theory and applications to earthquake engineering, by Anil K. Chopra, Prentice-Hall, Englewood Cliffs, NJ, 1995. no. of pages: xxviii + 761, ISBN 0-13-855214-2," Earthquake Engineering \& Structural Dynamics, vol. 24, no. 8, p. 1173, 1995.

[30] C.-M. Uang and V. V. Bertero, "Evaluation of seismic energy in structures," Earthquake Engineering \& Structural Dynamics, vol. 19, no. 1, pp. 77-90, 1990.

[31] S. Szyniszewski and T. Krauthammer, "Energy flow in progressive collapse of steel framed buildings," Engineering Structures, vol. 42, pp. 142-153, 2012.

[32] A. Sainoki and H. S. Mitri, "Effect of slip-weakening distance on selected seismic source parameters of mining-induced fault-slip," International Journal of Rock Mechanics and Mining Sciences, vol. 73, pp. 115-122, 2015.

[33] Z. Z. Wang, Y. J. Jiang, and C. A. Zhu, "Seismic energy response and damage evolution of tunnel lining structures," European Journal of Environmental and Civil Engineering, vol. 23, no. 6, pp. 758-770, 2017.

[34] H. Zhou and J. Li, "Effective energy criterion for collapse of deteriorating structural systems," Journal of Engineering Mechanics, vol. 143, Article ID 0401713512, 2017.

[35] J. Xu and J. Li, "An energetic criterion for dynamic instability of structures under arbitrary excitations," International Journal of Structural Stability and Dynamics, vol. 15, no. 2, Article ID 1450043, 2015.

[36] J. Ma, L. Dong, G. Zhao, and X. Li, "Ground motions induced by mining seismic events with different focal mechanisms," International Journal of Rock Mechanics and Mining Sciences, vol. 116, pp. 99-110, 2019.

[37] H. Xu, T. Li, L. Xia, J. X. Zhao, and D. Wang, "Shaking table tests on seismic measures of a model mountain tunnel," Tunnelling and Underground Space Technology, vol. 60, pp. 197-209, 2016.

[38] S. Shirzadegan, E. Nordlund, and P. Zhang, "large scale dynamic testing of rock support system at Kiirunavaara underground mine," Rock Mechanics and Rock Engineering, vol. 49, no. 7, pp. 2773-2794, 2016.

[39] Q. M. Li, "Strain energy density failure criterion," International Journal of Solids and Structures, vol. 38, pp. 6997-7013, 2001.

[40] J. Yang, D. Yang, X. Zhang et al., "Energy budget and fast rupture on a near-excavation fault: implications for mitigating induced seismicity," Journal of Geophysical Research: Solid Earth, vol. 125, no. 10, 2020.

[41] J. Yu and Z. Z. Wang, "The dynamic interaction of the soiltunnel-building system under seismic waves," Soil Dynamics and Earthquake Engineering, vol. 144, no. 5, Article ID 106686, 2021.

[42] N.-A. Do, D. Dias, P. Oreste, and I. Djeran-Maigre, "2D numerical investigation of segmental tunnel lining under seismic loading," Soil Dynamics and Earthquake Engineering, vol. 72, pp. 66-76, 2015.

[43] L. Hu, Y. Li, X. Liang, C. a. Tang, and L. Yan, "Rock damage and energy balance of strainbursts induced by low frequency seismic disturbance at high static stress," Rock Mechanics and Rock Engineering, vol. 53, no. 11, pp. 4857-4872, 2020. 
[44] H. Yu, Y. Yang, and Y. Yuan, "Analytical solution for a finite Euler-Bernoulli beam with single discontinuity in section under arbitrary dynamic loads," Applied Mathematical Modelling, vol. 60, pp. 571-580, 2018.

[45] Y. Yang, H. Yu, Y. Yuan, and M. Zhao, "Analytical solution for longitudinal seismic response of long tunnels subjected to Rayleigh waves," International Journal for Numerical and Analytical Methods in Geomechanics, vol. 44, no. 10, pp. 1371-1385, 2020.

[46] E. D. Steffler, J. S. Epstein, and E. G. Conley, "Energy partitioning for a crack under remote shear and compression," International Journal of Fracture, vol. 120, no. 4, pp. 563-580, 2003.

[47] Z.-X. Li, C.-H. Li, and J.-B. Yan, "Seismic behaviour of hybridfibre reinforced concrete shear keys in immersed tunnels," Tunnelling and Underground Space Technology, vol. 88, pp. 16-28, 2019.

[48] S. Sun, S. Li, L. Li et al., "Slope stability analysis and protection measures in bridge and tunnel engineering: a practical case study from southwestern China," Bulletin of Engineering Geology and the Environment, vol. 78, no. 5, pp. 3305-3321, 2018. 